\title{
Arthropod Development's Response to Temperature: a Review and New Software for Modeling
}

\section{Authors: Mohammad Ali Mirhosseini, Yaghoub Fathipour, and Gadi V. P. Reddy}

This is a pre-copyedited, author-produced PDF of an article accepted for publication in Annals of the Entomological Society of America following peer review. The version of record, see complete citation below, is available online at: https://dx.doi.org/10.1093/aesa/sax071.

Mirhosseini, Mohammad Ali, Yaghoub Fathipour, and Gadi V. P. Reddy. "Arthropod Development's Response to Temperature: a Review and New Software for Modeling." Annals of the Entomological Society of America 110, no. 6 (November 2017): 507-520. DOI: 10.1093/aesa/ sax071. 


\title{
Arthropod Development's Response to Temperature: a Review and New Software for Modeling
}

\author{
Mohammad Ali Mirhosseini, ${ }^{1}$ Yaghoub Fathipour, ${ }^{1,2}$ and Gadi V. P. Reddy ${ }^{3}$
}

'Department of Entomology, Faculty of Agriculture, Tarbiat Modares University, P.O. Box 14115-336, Tehran, Iran, ${ }^{2}$ Corresponding author, email: fathi@modares.ac.ir, and ${ }^{3}$ Montana State University, Department of Research Centers, Western Triangle Agricultural Research Center, 9546 Old Shelby Road, P.O. Box 656, Conrad, MT 59425

\begin{abstract}
Among environmental factors, temperature has a direct and crucial influence on the key life processes of survival, development, reproduction, and movement of poikilothermic animals and hence their population dynamics. The lower and upper temperature thresholds and optimal temperature have ramifications for all major life processes, where within a specific range, a temperature change results in a proportional rise or fall of the rate of any given process. There are some basic approaches for modeling development response to temperature in arthropods. The oldest and most widely used model is a simple linear description of arthropod development in relation to temperature. The linear model forms the basis of the well-known thermal summation or degree-day (DD) approach to timing prediction. The second approach for predicting arthropod development rate is nonlinear mathematical models. However, given the fundamental role of thermal models in forecasting and integrated pest management programs, the main purpose of this paper was to facilitate the use of thermal models to estimate the developmental response of arthropods to temperature and select the appropriate model with a view to goodness-of-fit and generalizability by designing a user-friendly software. In this paper, the linear and most common nonlinear thermal models and the main criteria for selecting appropriate models are also reviewed.
\end{abstract}

Environmental conditions, and especially temperature, have a profound effect on the biology and life-history of poikilothermic animals such as arthropods. In addition to development time, survivorship, demographic parameters, prey consumption, and foraging behavior of arthropods can all be affected by temperature (Zamani et al. 2006, Pakyari et al. 2009, Aghdam et al. 2009a, Ganjisaffar et al. 2011a, Jafari et al. 2012a, Kouhjani-Gorji et al. 2012). As temperature sets the limits of biological performance in arthropods, the low and high temperature thresholds along with the optimal temperature should be taken into consideration for all major life processes, since within a specific range, any temperature change results in a proportional rise or fall of the rate of any given process (Roy et al. 2002). Knowledge of arthropod (especially insect and mite) adaptations to climatic conditions plays a vital role in pest management, allowing the forecasting of development, reproduction, dormancy, and migration (Nechols et al. 1999). Using mathematical models to describe the influence of temperature on arthropod development informs this forecasting ability.

Currently, phenological models are the most important and common tools for predicting the development of plant pests and their natural enemies around the world (Shi et al. 2017a). Relationships, often observed under laboratory conditions, between insect development rate (the reciprocal of development time) and temperature are commonly used by applied entomologists to predict the timing and phenology of insect life cycle events. This relationship is usually nonlinear throughout the range of temperatures in which a species can survive; however, a number of both linear and nonlinear mathematical functions have been used to describe it (Worner 2008). There are three basic approaches for modeling arthropod development in relation to temperature (Worner 2008). The oldest and most widely used model is a simple linear description of insect development in relation to temperature. This linear model forms the basis for the well-known thermal summation or degree-day (DD) approach to timing prediction. There is a large amount of literature on the application of this method in applied entomology (Golizadeh et al. 2007, 2008; Aghdam et al. 2009b; Zahiri et al. 2010). It should be noticed that the linear model is kept within the limits of the linear portion of the development rate curve (Fig. 1). This linear or DD model is easy to develop and use. The second approach is the use of nonlinear mathematical models to describe the development of arthropods as a nonlinear process (Kheradmand et al. 2007, Jafari et al. 2012b, Karimi-Malati et al. 2014). These functions can range from a simple 


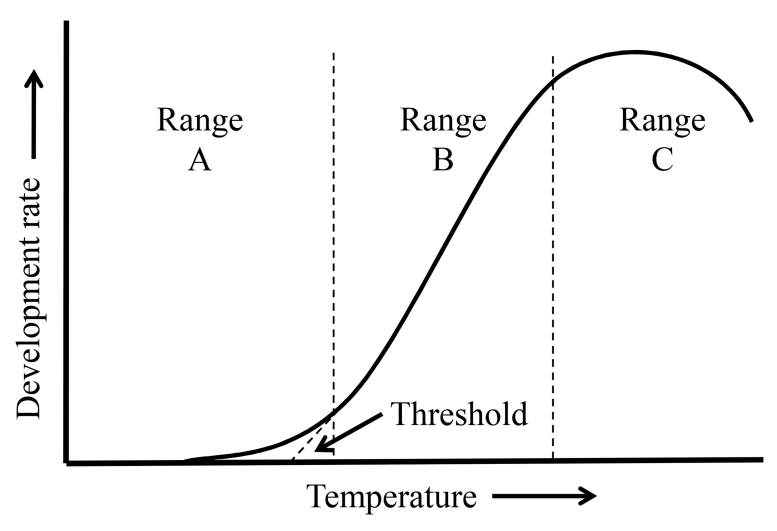

Fig. 1. The relationship between temperature and insect development rate, showing the nonlinear portions A, C, and the linear portion B (after Campbell et al. 1974).

sine-curve fitted to the nonlinear data to more complex biophysical models or equations. Nonlinear models require rate summation for timing prediction. The nonlinear portion of the development rate curve is shown in Fig. 1. For good precision, the time increment should be hourly. While these models provide a more accurate description of the developmental relationship, they are more difficult to develop and their practical application is more complicated. The third approach to life stage development in relation to temperature is represented by distribution models of insect phenology that include temperature-dependent development as well as variation in development rates within the population at any particular temperature. Such models require considerable research investment but can provide deep insight into the uncertainty of prediction and good estimates of limits to development in regions where the species is not normally found (Worner 2008). In general, however, complexity does not ensure more accuracy, and a comparative approach is often required. In addition, there can be differences in the performance of phenological models under variable temperature conditions that need to be taken into account.

Currently, no model provides an accurate description of development in all circumstances, especially under fluctuating conditions. Clearly, we are limited by the accuracy of the temperature data that are available, which may dictate the level of accuracy that is achievable. In many cases, when high accuracy is not necessary (or achievable) the simple DD approach may be all that is required.

Given the fundamental role of thermal models in forecasting and integrated pest management, the main goals of this paper are 1) to explain the experimental design for data collecting under both laboratory and field conditions for modeling, 2) to review the various linear and nonlinear thermal models (and their selection criteria) that have been used by different researchers to estimate thermal requirements and temperature thresholds for different arthropod species, and 3 ) to facilitate the use of the most common thermal models by designing user-friendly software, which will enable us to test a broad range of nonlinear models in a short time and choose the best model with statistical goodness-of-fit criteria.

\section{Determination of Physiological Time Based on DDs}

Physiological time can have different meanings, but in botany and entomology, physiological time refers to the 'heat unit approach' (Wang 1960) and is measured in DDs or degree-hours (Atkinson 1977). In other words, physiological time is the cumulative product of total time $\times$ temperature (above the threshold) (Dent 2000) and it is considered to be a thermal constant $(K)$ (Andrewartha and Birch 1954).

Before computing physiological time, an estimation of the arthropod's lower temperature threshold for development $\left(T_{0}\right.$ or $T_{\mathrm{L}}$ ) needs to be obtained. This temperature is often referred to as the lower temperature threshold (Kontodimas et al. 2004) or the zero development temperature (Howell and Neven 2000). However, at the lower temperature threshold, no measurable development is detected and thus the rate of development is taken as zero. In this scenario, therefore, cohorts of arthropods are held at constant temperatures to determine the development time of each life stage. Based on linear regression between development rate and temperature, the $T_{0}$ (temperature at which the development rate is zero) and the total effective temperature (thermal constant) can be determined (Campbell et al. 1974, Trudgill et al. 2005). Although using a linear method to calculate $T_{0}$ can be sufficiently accurate in most applications, other equations (including Analytis 1980, Briere et al. 1999 , etc.) are available for more accurate estimation. The other temperature threshold is the upper temperature threshold $\left(T_{\mathrm{U}}\right)$. At the upper temperature threshold, the rate of development is zero or life cannot be maintained for long. Most nonlinear models can estimate this temperature in a similar manner to the lower temperature threshold.

Despite the simplicity and accuracy of thermal constant estimation in the laboratory, it is a difficult and complicated process in the field due to temperature fluctuations. Although this process has been made easier and more reliable with the use of data logger devices (a portable electronic device that can record the hourly temperature and humidity in the field), there are other methods for calculating the total effective temperature based on daily minimum and maximum temperatures. Most of these techniques do not include all supplied temperatures but only work with environmental maximum and minimum temperatures and the lower temperature threshold, and they, therefore, only provide an estimation of the total effective temperature in a given environment (Baskerville and Emin 1969, Sevacherian et al. 1977, Roltsch et al. 1999).

\section{Calculation of Heat in Field Studies \\ The Rectangle Method}

This is the simplest approach for calculating heat units. In this case, heat units are calculated directly from the difference between the mean daily temperature and the $T_{0}$ with the following equation (Arnold 1960):

$$
\text { Heat unit }=\frac{T_{\max }+T_{\min }}{2}-T_{0}
$$

where $T_{\min }$ and $T_{\max }$ are minimum and maximum daily temperatures, respectively. This method is not as accurate as others because it ignores the upper temperature threshold.

\section{The Single-Triangle Method}

Since temperature in the field increases gradually to its maximum and then decreases over the course of $24 \mathrm{~h}$, some researchers believe that triangle methods could be more accurate than a rectangle approach (Sevacherian et al. 1977, Roltsch et al. 1999). This singletriangle method uses a day's low and high temperatures to produce an equilateral triangle over a $24-\mathrm{h}$ period, and then the DDs are estimated by calculating the area between the two thresholds that is enclosed by the triangle (Lindsey and Newman 1956). There are six different modes in this method (Zalom and Goodell 1983) (Fig. 2). 


\begin{tabular}{|c|c|c|}
\hline Heat unit $=\mathrm{T}_{\mathrm{U}}-\mathrm{T}_{0}$ & $\mathrm{~T}_{\mathrm{U}} \ldots \ldots$ & Heat unit $=\frac{6 \times\left(\mathrm{T}_{\max }+\mathrm{T}_{\min }-2 \mathrm{~T}_{0}\right)}{12}$ \\
\hline Heat unit $=\left(\frac{6 \times\left(\mathrm{T}_{\max }-\mathrm{T}_{0}\right)^{2}}{\mathrm{~T}_{\max }-\mathrm{T}_{\min }}\right) \div 12$ & $\begin{array}{l}\text { Heat unit }=\frac{6 \times\left(\mathrm{T}_{\max }+\mathrm{T} \min -2 \mathrm{~T}_{0}\right)}{12} \\
-\left[\left(\frac{6 \times\left(\mathrm{T}_{\max }-\mathrm{T}_{\mathrm{U}}\right)^{2}}{\mathrm{~T}_{\max }-\mathrm{T}_{\min }}\right) \div 12\right]\end{array}$ & $\begin{array}{l}\text { Heat unit }=\left[\frac{6 \times\left(\mathrm{T}_{\max }-\mathrm{T}_{0}\right)^{2}}{\mathrm{~T}_{\max }-\mathrm{T}_{\min }}\right. \\
\left.\frac{6 \times\left(\mathrm{T}_{\max }-\mathrm{T}_{\mathrm{U}}\right)^{2}}{\mathrm{~T}_{\max }-\mathrm{T}_{\min }}\right] \div 12\end{array}$ \\
\hline
\end{tabular}

Fig. 2. Equations for calculating heat unit by the single triangle method ( $T_{\max }:$ maximum daily temperature; $T_{\min }: \operatorname{minimum}$ daily temperature; $T U$ : upper temperature threshold; $T_{0}$ : lower temperature threshold).

\begin{tabular}{|c|c|c|}
\hline $\begin{array}{c}\mathrm{T}_{\mathrm{min}} \\
\mathrm{T}_{\mathrm{U}} \\
\text { Heat unit }=\frac{\mathrm{T}_{\mathrm{U}}-\mathrm{T}_{0}}{2}\end{array}$ & $\mathrm{~T}_{0}$ & Heat unit $=\frac{6 \times\left(\mathrm{T}_{\max }+\mathrm{T}_{\min }-2 \mathrm{~T}_{0}\right)}{24}$ \\
\hline Heat unit $=\left(\frac{6 \times\left(\mathrm{T}_{\max }-\mathrm{T}_{0}\right)^{2}}{\mathrm{~T}_{\max }-\mathrm{T}_{\min }}\right) \div 24$ & $\begin{array}{l}\text { Heat unit }=\frac{6 \times\left(\mathrm{T}_{\max }+\mathrm{T} \min -2 \mathrm{~T}_{0}\right)}{24} \\
-\left[\left(\frac{6 \times\left(\mathrm{T}_{\max }-\mathrm{T}_{\mathrm{U}}\right)^{2}}{\mathrm{~T}_{\max }-\mathrm{T}_{\min }}\right) \div 24\right]\end{array}$ & $\begin{array}{l}\mathrm{T}_{\mathrm{U}} \\
\mathrm{T}_{0} \ldots \\
\text { Heat unit }=\left[\frac{6 \times\left(\mathrm{T}_{\max }-\mathrm{T}_{0}\right)^{2}}{\mathrm{~T}_{\max }-\mathrm{T}_{\min }}\right. \\
\left.\frac{6 \times\left(\mathrm{T}_{\max }-\mathrm{T}_{\mathrm{U}}\right)^{2}}{\mathrm{~T}_{\max }-\mathrm{T}_{\min }}\right] \div 24\end{array}$ \\
\hline
\end{tabular}

Fig. 3. Equations for calculating half-day heat unit by the double triangle method ( $T_{\max }: \operatorname{maximum}$ daily temperature; $T_{\min }: \operatorname{minimum}$ daily temperature; TU: upper temperature threshold; $T_{0}$ : lower temperature threshold).

\section{The Double-Triangle Method}

In this method, daily effective temperatures are calculated for every $12-\mathrm{h}$ period, and then a straight line is drawn between the minimum and maximum temperatures of the day and the area between thresholds that falls within the resulting triangle for first half-day heat unit is calculated (Sevacherian et al. 1977, Roltsch et al. 1999) (Fig. 3). This approach then fits another straight line between the maximum temperature of that day and the minimum temperature of the next day to calculating a second half-day heat unit.

\section{The Single-Sine Method}

Sine-wave methods are used more often than others to estimate daily effective temperature. These methods assume that daily temperature variation adheres to a sine-shaped curve. This sine shaped curve is created based on minimum and maximum daily temperatures, and daily effective temperature is equal to the area under the curve between the lower and upper threshold temperatures (Baskerville and Emin 1969). This single-sine method uses the minimum and maximum temperatures of each day to draw a sine shaped curves and calculate the heat units (Fig. 4).

\section{The Double-Sine Method}

The only difference between this approach and the single-sine method is that this method (Fig. 5) draws a sine curve through the minimum and maximum temperatures of the day to establish a first half-day heat unit. It then fits another sine curve through the maximum 


\begin{tabular}{|c|c|c|}
\hline $\begin{array}{c}\mathrm{T}_{\mathrm{U}} \mathrm{I}_{\min } \\
\mathrm{T} \mathrm{T}_{0} \ldots \mathrm{t} \text { unit }=\mathrm{T}_{\mathrm{U}}-\mathrm{T}_{0}\end{array}$ & Heat unit $=0$ & Heat unit $=\mathrm{b}-\mathrm{T}_{0}$ \\
\hline $\begin{aligned} \text { Heat unit } & =\frac{1}{\Pi} \times\left[\left(b-\mathrm{T}_{0}\right) \times\left(\frac{\Pi}{2}-\theta_{1}\right)\right. \\
& \left.+\left(\mathrm{a} \times \cos \left(\theta_{1}\right)\right)\right]\end{aligned}$ & $\begin{array}{l}\mathrm{T}_{\mathrm{U}} \\
\text { Heat unit }=\frac{1}{\Pi} \times\left\{\left[\left(b-\mathrm{T}_{0}\right) \times\left(\theta_{2}+\frac{\Pi}{2}\right)\right]\right. \\
\left.+\left[\left(\mathrm{T}_{\mathrm{U}}-\mathrm{T}_{0}\right) \times\left(\frac{\Pi}{2}-\theta_{2}\right)\right]-\left[\mathrm{a} \times \cos \left(\theta_{2}\right)\right]\right\}\end{array}$ & $\begin{array}{l}\text { Heat unit }=\frac{1}{\Pi} \times\left\{\left[\left(b-\mathrm{T}_{0}\right) \times\left(\theta_{2}-\theta_{1}\right)\right]\right. \\
+\left[\mathrm{a} \times\left(\cos \left(\theta_{1}\right)-\cos \left(\theta_{2}\right)\right)\right] \\
\left.\quad+\left[\left(\mathrm{T}_{\mathrm{U}}-\mathrm{T}_{0}\right) \times\left(\frac{\Pi}{2}-\theta_{2}\right)\right]\right\}\end{array}$ \\
\hline
\end{tabular}

Fig. 4. Equations for calculating heat unit by the single sine method ( $T_{\max }$ : maximum daily temperature; $T_{\min }:$ minimum daily temperature; $T U$ : upper temperature threshold; $T_{0}$ : lower temperature threshold; $\left.\left.\mathrm{a}=\frac{(\operatorname{Tmax}-\operatorname{Tmin})}{2} ; \mathrm{b}=\frac{(\operatorname{Tmax}+\operatorname{Tmin})}{2} ; \theta_{2}=\sin ^{-1}\left[\left(\mathrm{~T}_{\mathrm{U}}-\mathrm{b}\right) \div \mathrm{a}\right]\right) ; \theta_{2}=\sin ^{-1}\left[\left(\mathrm{~T}_{\mathrm{U}}-\mathrm{b}\right) \div \mathrm{a}\right]\right)$.

\begin{tabular}{|c|c|c|}
\hline $\begin{array}{c}\mathrm{T}_{\mathrm{U}} \mathrm{T}_{\min } \\
\mathrm{T}_{0} \mathrm{C} \\
\text { Heat unit }=\frac{\mathrm{T}_{\mathrm{U}}-\mathrm{T}_{0}}{2}\end{array}$ & $\mathrm{~T}_{\mathrm{U}}$ & $\mathrm{T}_{0}$ \\
\hline $\begin{array}{c}\mathrm{T}_{\mathrm{U}} \\
\text { Heat unit }=\frac{1}{2 \Pi} \times\left[\left(b-\mathrm{T}_{0}\right) \times\left(\frac{\Pi}{2}-\theta_{1}\right)\right. \\
\left.+\left(\mathrm{a} \times \cos \left(\theta_{1}\right)\right)\right]\end{array}$ & $\begin{array}{l}\mathrm{T}_{\mathrm{U}} \\
\text { Heat unit }=\frac{1}{2 \Pi} \times\left\{\left[\left(b-\mathrm{T}_{0}\right) \times\left(\theta_{2}+\frac{\Pi}{2}\right)\right]\right. \\
\left.+\left[\left(\mathrm{T}_{\mathrm{U}}-\mathrm{T}_{0}\right) \times\left(\frac{\Pi}{2}-\theta_{2}\right)\right]-\left[\mathrm{a} \times \cos \left(\theta_{2}\right)\right]\right\}\end{array}$ & $\begin{array}{l}\mathrm{T}_{0} \\
\text { Heat unit }=\frac{1}{2 \Pi} \times\left\{\left[\left(b-\mathrm{T}_{0}\right) \times\left(\theta_{2}-\theta_{1}\right)\right]\right. \\
+\left[\operatorname{a} \times\left(\cos \left(\theta_{1}\right)-\cos \left(\theta_{2}\right)\right)\right] \\
\left.+\left[\left(\mathrm{T}_{\mathrm{U}}-\mathrm{T}_{0}\right) \times\left(\frac{\Pi}{2}-\theta_{2}\right)\right]\right\}\end{array}$ \\
\hline
\end{tabular}

Fig. 5. Equations for calculating half-day heat unit by the double sine method $\left(T_{\max }\right.$ : maximum daily temperature; $T_{\min }: \operatorname{minimum}$ daily temperature; $T U:$ upper temperature threshold; $T_{0}$ : lower temperature threshold; $\left.\mathrm{a}=\frac{(\operatorname{Tmax}-\operatorname{Tmin})}{2} ; \mathrm{b}=\frac{(\operatorname{Tmax}+\operatorname{Tmin})}{2} ; \theta_{1}=\sin ^{-1}\left[\left(T_{0}-b\right) \div a\right] ; \theta_{2}=\sin ^{-1}\left[\left(\mathrm{~T}_{U}-\mathrm{b}\right) \div \mathrm{a}\right]\right)$.

temperature of the same day and the minimum temperature of the next day to establish a second half-day heat unit (Allen 1976).

Sine methods more closely estimate actual heat units than others, particularly if the minimum temperature is below the lower temperature threshold (Pruess 1983). However, these two sine methods' equations are not easy for farmers to use since they require some complicated calculations.

\section{Setting a Date to Initiate Accumulation of Heat Units in Field}

To prevent errors in any DD method in the field, the starting time for accumulating heat units (the 'biofix' or Day 0 ) is very important. In other words, 'biofix' refers to the date at which an arthropod (or other poikilothermic animal or plant) starts to develop. This date differs with species. In plants, the planting date can be considered 
the biofix, but determining this date for arthropods is more difficult. Some researchers believe that the starting date for many pests can be determined according to the calendar (e.g., 1 January) (Johnson et al. 1998). This method may not be useful, however, because of difference in the overwintering patterns of different insect species. In addition, the accumulation of heat units long before any arthropod development occurs can be another disadvantage. Another method for determining the biofix is using some event in the arthropod life cycle. For example, the date of the first capture (or capture in two consecutive days) of an adult in a trap can be used as a starting date for accumulating DDs. When using different starting dates to accumulate heat units for an event (e.g., level of pest attack), the best biofix may be the date with the smallest standard deviation for the heat sum accumulations (Fatzinger and Dixon 1996).

\section{Thermal Modeling}

Although the process of relating environmental temperature to the development time of some animals is about $270 \mathrm{yr}$ old (Young and Young 1998), the main attempts to relate temperature to arthropod development go back to the research of two scientists on Cydia pomonella (L.) (Lepidoptera: Tortricidae) (Sandehson 1910, Glenn 1922). Since then, different types of models have been suggested to describe the relationship between temperature and arthropod development (Ludwig 1928, Davidson 1942, Pradhan 1945, Stinner et al. 1974, Logan et al. 1976, Analytis 1977, Sharpe and DeMichele 1977, Lactin et al. 1995,Briere et al. 1999). These models differ in their number of parameters and assumptions on temperature effects around lower and upper thresholds (Roy et al. 2002). However, thermal models have been frequently used to forecast the occurrence and seasonal fluctuation of pests and natural enemy populations under field conditions, to determine appropriate conditions for mass production of natural enemies and in modeling tritrophic interactions in different ecosystems associated with possible consequences of global warming (Tobin et al. 2001, Logan et al. 2006, Jafari et al. 2010, Pakyari et al. 2011a).

\section{Linear Models}

According to the 'total effective temperature' principle (equation 2), two models are used to estimate the related parameters: the ordinary (common) regression model (Ludwig 1928, Campbell et al. 1974, Frazer and McGregor 1992, Lopez-Arroyo et al. 1999, Roy et al. 2002) and the Ikemoto regression model (Ikemoto and Takai 2000). These models are extensively used to determine thermal constants $(K)$ and lower temperature thresholds $\left(T_{0}\right)$. In these models, only the rate of development indicated by the linear part of the developmental curve (Fig. 1) is used and data that deviated from the straight line were omitted. This omission is necessary for the correct calculation of $T_{0}$ and $K$ (De Clerq and Degheele 1992).

$$
D\left(T-T_{0}\right)=K
$$

where $D, T, T_{0}$, and $K$ are development time, environmental temperature, lower temperature threshold, and thermal constant, respectively.

\section{Ordinary Linear Model or DD Model}

In this model, the effect of temperature on development rate (the reciprocal of development time) is calculated using the following equation:

$$
R=a+b T
$$

where $T$ is the temperature, $R$ is the development rate, and $a$ and $b$ are constant parameters. This model uses ordinary least squares (OLS) method to carry out the linear fitting. The lower temperature threshold $\left(T_{0}\right)$ and its standard error (SE) have been calculated by the following equations, respectively.

$$
\begin{gathered}
T_{0}=\frac{-a}{b} \\
\mathrm{SE}_{T_{0}}=\frac{\bar{r}}{b} \sqrt{\frac{s^{2}}{N \times \bar{r}^{2}}+\left(\frac{\mathrm{SE}_{b}}{b}\right)^{2}}
\end{gathered}
$$

where $s^{2}$ is the residual mean square of $r, \bar{r}$ is the sample mean, and $N$ is the sample size (Campbell et al. 1974, Kontodimas et al. 2004)

Meanwhile, thermal constant $(K)$ and also its standard error (SE) can be calculated as follows (Campbell et al. 1974, Kontodimas et al. 2004):

$$
\begin{gathered}
K=\frac{1}{b} \\
\mathrm{SE}_{K}=\frac{\mathrm{SE}_{b}}{b^{2}}
\end{gathered}
$$

Although this linear model enables us to calculate $T_{0}$ and $K$, the estimated threshold is an extrapolation of the regression beyond the linear portion, making it common to overestimate the lower temperature threshold $\left(T_{0}\right)$ and underestimate the thermal constant $(K)$ at temperatures close to the lower temperature threshold (Davidson 1944). Furthermore, this model provides neither the upper temperature threshold $\left(T_{U}\right)$ nor the optimal temperature ( $T_{\text {opt }}$, temperature that developmental rate is maximum). However, despite its fundamental shortcomings, this model has been widely used because it has the advantages of simplicity and ease in estimating the thermal constant (Worner 1992), has minimum data requirements for formulation, and is reasonably accurate. Furthermore, its differences from more complex models are minimal (Wagner et al. 1984), and consequently it has been widely used (Campbell et al. 1974; Kheradmand et al. 2006; Zamani et al. 2006, 2007; Haghani et al. 2007a,b; Taghizadeh et al. 2008).

\section{Ikemoto Linear Model}

The lower temperature threshold and thermal constant are calculated using the following equation (Briere et al. 1999):

$$
\frac{1}{D}=\left(\frac{-T_{0}}{K}\right)+\left(\frac{1}{K}\right) T
$$

where $D$ is the development time at temperature $T$, and $T_{0}$ and $K$ are the lower temperature threshold and thermal constant, respectively. However, Ikemoto and Takai (2000) have pointed out three problems with the use of this equation, the first being that detecting the optimum temperature range is usually difficult with this equation. The second problem is that when utilizing this equation, the weights of data points are disproportionate between those in the upper and lower parts of the line, and they are not homogeneous along the temperature axis. The third problem is that in most of data, the errors in the $x$-variable are ignored. These second and third problems, in most cases, will result in a decrease in the slope of the line, a lower $T_{0}$, and a higher $K$ (Ikemoto and Takai 2000). Therefore, Ikemoto and Takai 
proposed another linear model based on the following development time formula:

$$
\mathrm{DT}=K+T_{0} D
$$

where $D$ is development time, $T$ is the temperature, $T_{0}$ is the lower temperature threshold, and $K$ is the thermal constant. This equation uses the reduced major axis method to carry out the linear fitting. The Ikemoto linear model represents a straight line with $X=D$ and $Y=D T$ (Ikemoto and Takai 2000).

The lower temperature threshold and thermal constant of various insects have been estimated by this model (Kheradmand et al. 2007, Gorji et al. 2008, Aghdam et al. 2009b, Ganjisaffar et al. 2011b, Pakyari et al. 2011b, Jafari et al. 2012b). Some researchers have used both ordinary and Ikemoto models and their results have revealed that the model proposed by Ikemoto had a higher accuracy than the ordinary regression model (Gorji et al. 2008, Ganjisaffar et al. 2011b, Pakyari et al. 2011b). However, some other studies have found both linear models to have the same degree of accuracy in estimating $T_{0}$ and $K$ (Aghdam et al. 2009b, Zahiri et al. 2010).

\section{NonLinear Models}

Linear models do not provide either the optimal temperature $\left(T_{\text {opt }}\right)$ or the upper temperature threshold $\left(T_{\mathrm{U}}\right)$, and hence, a number of nonlinear models have been applied to estimate these crucial temperatures (Aghdam et al. 2009a, Pakyari et al. 2011b, Golizadeh et al. 2008). The curvilinear relationship of development time versus temperature (Fig. 1) has been evaluated by nonlinear models. These models have a different number of parameters. In addition, basic assumptions on temperature effects near lower and upper limits of each nonlinear model are different from the others (Roy et al. 2002). Most models can estimate the two temperature thresholds directly (e.g., Analytis, Briere, and Performance). Some of the common mathematical models (linear and nonlinear) used to describe the effect of temperature on the development rate of arthropods are listed in Table 1. Only one of the listed models in Table 1 could estimate the temperature thresholds and optimum temperature directly (Beta model). However, these parameters were either directly estimated by the fitted model or they were obtained mathematically using graphic software (e.g., Advanced Grapher, Graph Plotter, and Excel) (Zahiri et al. 2010).

\section{The Pradhan -Taylor Model}

The Pradhan-Taylor model is a simple normal function written as follows (equation 10) (Pradhan 1945, Taylor 1981):

$$
R(T)=R_{\mathrm{m}} \times \exp \left[\frac{-1}{2}\left(\frac{T-T_{\mathrm{m}}}{T_{\sigma}}\right)^{2}\right]
$$

where $R(T)$ is the development rate at temperature $T, R_{\mathrm{m}}$ is the maximum development rate, $T_{\mathrm{m}}$ is the temperature where the development rate is highest (optimum temperature), and $T_{\sigma}$ is a shape parameter giving the spread of the curve. This model was applied in thermal requirements studies of different arthropods (Roy et al. 2002,Kontodimas et al. 2004, Gorji et al. 2008, Aghdam et al. 2009b, Golizadeh and Zalucki 2012), and it is recommended for the description of temperature-dependent development of the predatory nabid bug Nabis capsiformis Germar (Hemiptera: Nabidae) (Arbab et al. 2016).

\section{The Davidson (Logistic) Model}

The Davidson or logistic model (Davidson 1942, Davidson 1944) produces a curve that approaches an asymptote at temperatures
Table 1. Some of the most common mathematical models used to describe the effect of temperature on the development rate of arthropods and their ability to estimate four important biological

\begin{tabular}{|c|c|c|c|c|}
\hline Model & $T_{0}$ & $T_{\text {opt }}$ & $T_{U}$ & K \\
\hline Ordinary linear model & + & - & - & + \\
\hline Ikemoto linear model & + & _- & _- & + \\
\hline Pradhan-Taylor & - & + & - & - \\
\hline Davidson (Logistic) & - & - & - & - \\
\hline Logan-6 & - & - & + & - \\
\hline Logan-10 & - & - & + & - \\
\hline Hilbert and Logan & + & - & + & - \\
\hline Lactin-1 & - & - & + & - \\
\hline Lactin-2 & - & - & + & - \\
\hline Analytis-1 & + & - & + & - \\
\hline Analytis-2 & + & - & + & - \\
\hline Analytis-3 & + & - & + & - \\
\hline Analytis-1/Allahyari & + & - & + & - \\
\hline Analytis-3/Kontodimas & + & - & + & - \\
\hline Briere-1 & + & - & + & - \\
\hline Briere-2 & + & - & + & - \\
\hline Janisch/Kontodimas & - & + & - & - \\
\hline Janisch/Rochat & - & - & + & - \\
\hline Sharpe and DeMichele & - & - & - & - \\
\hline Sharpe and DeMichele/Schoolfield & - & - & - & - \\
\hline Sharpe and DeMichele/Kontodimas & - & - & - & - \\
\hline Sharpe-Schoolfield-Ikemoto (SSI) model & - & + & - & - \\
\hline Polynomial 3rd order & - & - & - & - \\
\hline Performance-1 & + & - & + & - \\
\hline Performance- 2 & + & - & + & - \\
\hline Ratkowsky & + & - & + & - \\
\hline Wang & + & - & + & - \\
\hline Beta & + & + & + & - \\
\hline
\end{tabular}
parameters

$T_{0}, T_{\text {opt }}, T_{\mathrm{U}}$, and $K$ are lower temperature threshold, optimum temperature, upper temperature threshold, and thermal constant, respectively. The plus and minus signs indicate whether the model is able to estimate the parameter directly or not, respectively.

around the optimum but does a poor job describing the rates at high temperatures. This model is defined as follows:

$$
R(T)=\frac{K}{1+\mathrm{e}^{a-b T}}
$$

where $R(T)$ is the development rate at temperature $T ; a, b$, and $K$ are constants and represent the value which defines the place of the regression line in relation to the $\mathrm{x}$-axis, the slope of the curve line, and the upper limit of the sigmoid line, respectively. Several researchers have estimated the development rate of different insects using this model (Kontodimas et al. 2004; Medeiros et al. 2004; Arbab et al. 2006, 2008; Golizadeh et al. 2007; Gorji et al. 2008; Aghdam et al. 2009b; Zahiri et al. 2010; Pakyari et al. 2011b; Golizadeh and Zalucki 2012).

\section{Logan's Models}

The Logan-6 model (Logan et al. 1976) is formed of two exponential equations to determine development rate at intermediate and higher temperatures. After many experiments, Logan's group revealed that the response of phase I (in Logan-6) was more sigmoid-shaped than exponential. Modifications were made, resulting in another equation (Logan-10), which had an excellent description of development rates; moreover, many of its parameters are biologically important and meaningful. Logan's models were more 
descriptive than their own predecessors and they had parameters that can be interpreted biologically, but they were unable to estimate the lower temperature threshold $\left(T_{0}\right)$. To evaluate thermal requirements of several arthropods, many research workers used these models (Bryant et al. 2002; Roy et al. 2002; Kontodimas et al. 2004; Arbab et al. 2006, 2008; Haghani et al. 2007a,b; Kheradmand et al. 2007; Golizadeh et al. 2008; Gorji et al. 2008; Aghdam et al. 2009b; Arbab and Mcneill 2011; Ganjisaffar et al. 2011b; Tazerouni et al. 2013).

The Logan- 6 model is defined as follows:

$$
R(T)=\psi\left[\mathrm{e}^{\rho T}-\mathrm{e}^{\rho T_{\mathrm{U}}-\tau}\right], \quad \tau=\frac{T_{\mathrm{U}}-T}{\Delta_{T}}
$$

here $R(T)$ is the development rate at temperature $T, \Psi$ is the development rate at some base temperature above the developmental threshold, $\rho$ is a constant defining the rate at the optimal temperature, $T_{\mathrm{U}}$ is the upper temperature threshold, and $\Delta_{\mathrm{T}}$ is the temperature range over which physiological breakdown becomes the overriding influence.

The Logan-10 model is defined as follows:

$$
R(T)=a\left[\frac{1}{1+K \mathrm{e}^{-\rho T}}-\mathrm{e}^{-\tau}\right], \quad \tau=\frac{T_{\mathrm{U}}-T}{\Delta_{T}}
$$

where $a$ and $K$ are empirical constants, and $R(T), \rho, T_{\mathrm{U}}$, and $\Delta_{\mathrm{T}}$ are the same as in the Logan- 6 model. This model provided the best estimation of temperature thresholds for the phorid fly Megaselia halterata (Wood) (Diptera: Phoridae) and was strongly recommended for a description of the temperature-dependent development of this insect (Barzegar et al. 2016).

\section{The Hilbert and Logan Model}

The Hilbert and Logan model (Hilbert and Logan 1983), a combination of sigmoid and exponential equations, was formulated to improve the Logan model by providing a lower temperature threshold. This model, which has been used in a number of studies (Aghdam et al. 2009b, Zahiri et al. 2010, Arbab and Mcneill 2011, Arbab et al. 2016), is defined as follows:

$$
R(T)=\psi\left[\frac{\left(T-T_{0}\right)^{2}}{\left(T-T_{0}\right)+D^{2}}\right]-\mathrm{e}^{-\left(\left[T_{U}-\left(T-T_{0}\right)\right] / \Delta T\right)}
$$

where $R(T)$ is the development rate at temperature $T, \Psi$ and $\Delta T$ are the same as in the Logan-6 model, and $T_{U}, T_{0}$, and $D$ are the upper temperature threshold, lower temperature threshold, and constant empirical parameter, respectively. Modeling of the temperature-dependent development of the aphid Aphis pomi DeGeer (Hemiptera: Aphididae) using nonlinear models suggested that this model combined with Lactin-2 can be a suitable combination for fitting data (Arbab et al. 2006).

\section{Lactin's Models}

Two modifications of the Logan- 6 model were proposed by Lactin et al. (1995). First, they eliminated a redundant parameter to obtain the Lactin-1 model. Then they incorporated an intercept parameter, which allows the estimation of a lower temperature threshold for development, resulting in the Lactin-2 model. These models have been extensively used by researchers (Roy et al. 2002; Kontodimas et al. 2004; Golizadeh et al. 2007, 2008; Zamani et al. 2007; Jalali et al. 2010, 2014; Zahiri et al. 2010; Ganjisaffar et al. 2011b; Sandhu et al. 2013; Wang et al. 2013). These two models are defined as follows (equation 15 is Lactin-1 and equation 16 is Lactin-2):

$$
\begin{gathered}
R(T)=\exp (\rho T)-\exp \left[\rho T_{\mathrm{U}}-\frac{T_{\mathrm{U}}-T}{\Delta}\right] \\
R(T)=\exp (\rho T)-\exp \left(\rho T_{\mathrm{U}}-\frac{T_{\mathrm{U}}-T}{\Delta}\right)+\lambda
\end{gathered}
$$

where $R(T)$ is the development rate at temperature $T, T_{\mathrm{U}}$ is upper temperature threshold, $\rho$ and $\Delta$ are as in the Logan- 6 model, and $\lambda$ forces the curve to intercept the $y$-axis at a value below zero and thus allows the estimation of a low temperature threshold.

Although Jalali et al. (2010) noted that the Lactin-2 model may overestimate the upper temperature thresholds of different developmental stages of the coccinellid beetle Adalia bipunctata (L.) (Coleoptera: Coccinellidae), some studies have found this model to work well for estimating temperature thresholds for ladybird beetles (Roy et al. 2002, Kontodimas et al. 2004, Jalali et al. 2014). Another study claimed that among some models (e.g., Briere and Hilbert and Logan), this model was the most suitable to estimate the critical temperatures for the weevil Sitona lepidus Gyll. (Coleoptera: Curculionidae) (Arbab and Mcneill 2011). Furthermore, Lactin-2 and Sharp and DeMichele models can be two of the most efficient nonlinear models for estimating the temperature thresholds for Sitona discoideus Gyllenhal (Coleoptera: Curculionidae) (Arbab et al. 2008). Fitting data of the development period of shot-hole borer Xyleborus fornicates Eichh. (Coleoptera: Scolytidae) at different temperatures to some nonlinear models showed that Lactin-2 gave the best-fitted data (Walgama and Zalucki 2006). All of these results suggest that this model has good potential for modeling the temperature-dependent development of coleopteran insects.

\section{Analytis's Models}

Some empirical models were initially developed to account for both lower and upper temperature thresholds of a pathogenic fungus (Analytis 1977, Analytis 1980). Since then, these models have been widely used in arthropods, especially insects (Kontodimas et al. 2004; Arbab et al. 2006, 2008; Aghdam et al. 2009a, 2011; Zahiri et al. 2010; Golizadeh and Zalucki 2012). First, the Analytis-1 model is defined as follows:

$$
R(T)=P \delta^{n}(1-\delta)^{m}, \quad \delta=\frac{T-T_{0}}{T_{\mathrm{U}}-T_{0}}
$$

where $T_{0}$ and $T_{\mathrm{U}}$ are the lower and upper temperature thresholds, respectively. The parameters $P, n$, and $m$ are constants, where $n$ and $m$ are parameters controlling the skew and concavity of the curve, respectively. A more suitable and flexible model with broader application possibilities than Analytis-1 was built, named Analytis-2:

$$
R(T)=\left[P \delta^{n}(1-\delta)\right]^{m}, \quad \delta=\frac{T-T_{0}}{T_{\mathrm{U}}-T_{0}}
$$

All parameters in equation 18 are as in Analytis-1. Equation 19, meanwhile, represents the Analytis-3 model.

$$
R(T)=a\left(T-T_{0}\right)^{n}\left(T_{\mathrm{U}}-T\right)^{m}
$$

where $a$ is a constant parameter and all others are as in Analytis-1 and -2 . The literature review shows this model to be more frequently used than other Analytis models. This model was then 
modified to build the Analytis/Kontodimas (equation 20) model in 2004 (Kontodimas et al. 2004). The thermal requirements of several insects were evaluated using this model (Aghdam et al. 2009b, Zahiri et al. 2010):

$$
R(T)=a\left(T-T_{0}\right)^{2}\left(T_{\mathrm{U}}-T\right)
$$

Finally in 2005, the Analytis/Allahyari model (equation 21) was built by changing the Analytis-1 model (Allahyari 2005, Zahiri et al. 2010).

$$
R(T)=P \delta^{n}\left(1-\delta^{m}\right), \quad \delta=\frac{T-T_{0}}{T_{\mathrm{U}}-T_{0}}
$$

There is evidence that Analytis models, especially Analytis-2 and Analytis/Allahyari can be recommended to describe the temperaturedependent development of Hypera postica (Gyllenhal; Coleoptera: Curculionidae) (Zahiri et al. 2010).

\section{Briere's Models}

Briere et al. (1999) modified the Analytis-3 model and proposed two models with a nonlinear part at low and high temperatures and a linear portion at intermediate temperatures. These models are defined as follows (equation 22 is Briere-1 and equation 23 represents Brier-2):

$$
\begin{aligned}
& R(T)=a T\left(T-T_{0}\right)\left(T_{\mathrm{U}}-T\right)^{\frac{1}{2}} \\
& R(T)=a T\left(T-T_{0}\right)\left(T_{\mathrm{U}}-T\right)^{\frac{1}{n}}
\end{aligned}
$$

where $R(T)$ is the development rate at temperature $T, T_{0}$ and $T_{\mathrm{U}}$ are lower and upper temperature thresholds, respectively, and $a$ and $n$ are empirical constants. The efficiency of these models in estimating arthropod thermal requirements has been evaluated by several researchers (Roy et al. 2002; Arbab et al. 2006, 2008; Kontodimas et al. 2004; Zamani et al. 2006, 2007; Grout and Stoltz 2007; Kheradmand et al. 2007; Golizadeh et al. 2008; Gorji et al. 2008; Ganjisaffar et al. 2011b; Pakyari et al. 2011b; Karimi-Malati et al. 2014; Park et al. 2014). Park et al. (2014) showed that among three nonlinear models (Logan-6, Briere-1, and Performance-1), Briere-1 was the best at describing the temperature-dependent development of Cnaphalocrocis medinalis Guenee (Lepidoptera: Pyralidae). In addition, among eight nonlinear models, Briere's models were the best at estimating the temperature thresholds for Diuraphis noxia (Kurdjumov) (Hemiptera: Aphididae) (Tazerouni et al. 2013). Some researchers believe that Briere- 2 can be conclusively recommended for describing the temperature-dependent development of the Plutella xylostella (L.) (Lepidoptera: Plutellidae) (Golizadeh et al. 2007).

\section{Modified Janisch's Models}

The Janisch model was modified by Analytis in 1981 and Kontodimas in 2004, and finally the Janisch/Kontodimas model was developed (Janisch 1932, Analytis 1981, Kontodimas et al. 2004). This model is defined as follows:

$$
R(T)=\frac{2}{D_{\min }\left(\exp \left[K\left(T-T_{\text {opt }}\right)\right]+\exp \left[-\lambda\left(T-T_{\text {opt }}\right)\right]\right)}
$$

where $R(T)$ is the development rate at temperature $T, T_{\text {opt }}$ and $D_{\min }$ are optimum temperature and minimum development time (development time in optimum temperature), respectively, and $\lambda$ and $K$ are empirical constants. This model has been used to describe the effect of temperature on the development of a number of insects (Kontodimas et al. 2004, Zahiri et al. 2010, Barzegar et al. 2016).

Another nonlinear model was developed by Rochat and Gutierrez in 2001 based on the Janisch model. This model captures the correct shape of the relationship between temperature and development rate (Rochat and Gutierrez 2001).

$$
R(T)=\frac{2 c}{\left.a^{\left(T-T_{U}\right)}+b^{\left(T_{U}-T\right)}\right)}
$$

where $R(T)$ is the development rate at temperature $T, T_{\mathrm{U}}$ is upper temperature threshold, and $a, b$, and $c$ are constants parameters. This model has likewise been used to describe the temperature-dependent development of a number of insects (Rochat and Gutierrez 2001, Zahiri et al. 2010).

\section{Sharpe and DeMichele Models}

The Sharp and DeMichele biophysical model is based on the enzyme reaction rate theory (Sharpe and DeMichele 1977). This model is defined as follows:

$$
R(T)=\frac{T \mathrm{e}^{\left(\phi-\Delta H_{\mathrm{A}}{ }^{*} / T\right) / R}}{1+\mathrm{e}^{\left(\Delta S_{\mathrm{L}}-\Delta H_{\mathrm{L}} / T\right) / R}+\mathrm{e}^{\left(\Delta S_{\mathrm{H}}-\Delta H_{\mathrm{L}} / T\right) / R}}
$$

where $R(T)$ is the development rate at temperature $T, R$ is universal gas constant $\left(1.987 \mathrm{cal} \mathrm{degre}^{-1} \mathrm{~mole}^{-1}\right)$ which is independent of the organism, $\Phi$ is the thermodynamic constant parameter, $\Delta S_{\mathrm{L}}$ represents the change in entropy between states 1 and $2, \Delta S_{\mathrm{H}}$ represents the entropy of activation difference between states 2 and $3, \Delta H_{\mathrm{L}}$ is the change of enthalpy between states 1 and 2 at equilibrium, and $\Delta H_{\mathrm{A}}$ is enthalpy of activation. The values of five latest parameters are constants which reflect the individual thermodynamic characteristics of the organism's control enzyme system which is assumed to control development.

This model was reparametrized in 1981 and Sharp and DeMichele/Schoolfield model (equation 27) was developed as follows (Schoolfield et al. 1981):

$$
R(T)=\frac{\rho_{(23 \cdot c)} \frac{T}{298} \exp \left[\left(\Delta H_{A}^{*} / R\right)[(1 / 298)-(1 / T)]\right]}{1+\exp \left[\left(\Delta H_{\mathrm{L}} / R\right)\left[\left(1 / T_{y / 2 \mathrm{~L}}\right)-(1 / T)\right]\right]+\exp \left[\left(\Delta H_{\mathrm{H}} / R\right)\left[\left(1 / T_{v / 2 H}\right)-(1 / T)\right]\right]}
$$

In this model, $R(T)$ is the development rate at temperature $T, \rho$ is the developmental rate at $25^{\circ} \mathrm{C}, \Delta H_{\mathrm{A}}$ is the enthalpy of activation of reaction, $\Delta H_{\mathrm{L}}$ is the change in enthalpy at low temperature, $T_{1 / 2 \mathrm{~L}}$ is the temperature at which the enzyme for the low temperature portion is $1 / 2$ active, $\Delta H_{\mathrm{H}}$ is the change in enthalpy at high temperature, $T_{1 / 2 H}$ is the temperature at which the enzyme for the high temperature portion is $1 / 2$ active, and $R$ is as equation 26. Equation 26 was simplified in 2004 (Kontodimas et al. 2004) and the Sharpe and DeMichele/Kontodimas model (equation 28) was developed as follows:

$$
R(T)=\frac{T \exp (a-b / T)}{1+\exp (c-d / T)+\exp (f-g / T)}
$$

where $R(T)$ is the development rate at temperature $T ; a, b, c, d, f$, and $g$ are as in equation 26 .

Finally, the Sharp and DeMichele/Schoolfield model was greatly modified by Ikemoto in 2005 and the Sharpe-Schoolfield-Ikemoto 
(SSI) model (equation 29) was developed as follows (Ikemoto 2005, Ikemoto 2008):

$$
R(T)=\frac{\rho_{\Phi} \frac{T}{T_{\Phi}} \exp \left[\left(\Delta H_{\mathrm{\AA}} / R\right)\left[\left(1 / T_{\Phi}\right)-(1 / T)\right]\right]}{1+\exp \left[\left(\Delta H_{\mathrm{L}} / R\right)\left[\left(1 / T_{\mathrm{L}}\right) /(1 / T)\right]\right]+\exp \left[\left(\Delta H_{\mathrm{H}} / R\right)\left[\left(1 / T_{\mathrm{H}}\right)-(1 / T)\right]\right]}
$$

where $R(T)$ is the development rate at temperature $T, \rho_{\Phi}$ is the maximum development rate (development rate at optimum temperature) assuming no enzyme inactivation, $T_{\Phi}$ is the intrinsic optimum temperature at which the probability of an enzyme being in the active state is maximal, and $\Delta H_{\mathrm{A}}, \Delta H_{\mathrm{L}}, \Delta H_{\mathrm{H}}, T_{\mathrm{L}}, T_{\mathrm{H}}$, and $R$ are the same as in equation 27.

It is important to note that temperature in all four of these models is in Kelvin $\left(0^{\circ} \mathrm{C}=273.15 \mathrm{~K}\right)$. In addition, before using them it is important to determine the appropriate initial values of constants due to the variety of unknown parameters and model complexity. The algorithm used to calculate SSI model is accessible as the function in R software (Ikemoto et al. 2013). The literature review shows that these models, and especially the SSI model, have the potential to accurately describe the relationship between temperature and development rate in arthropods (Shi et al. 2017b). Moreover, all of these models are widely used to predict the development rate of a number of arthropods (Kim et al. 2001; Roy et al. 2002; Kontodimas et al. 2004; Medeiros et al. 2004; Arbab et al. 2006, 2008; Golizadeh et al. 2007; Kheradmand et al. 2007; Zahiri et al. 2010; Karimi-Malati et al. 2014).

The Polynomial Third-order Model

The polynomial third-order model or Harcourt equation proposed by Harcourt and Yee (1982) is defined as follows:

$$
R(T)=a_{0} T^{3}+a_{1} T^{2}+a_{2} T+a_{3}
$$

where $R(T)$ is the development rate at temperature $T$, and $a_{0}, a_{1}, a_{2}$ and $a_{3}$ are empirical constants. The efficiency of this model in estimating thermal constants of different arthropods has been evaluated by a number of researchers (Kontodimas et al. 2004, Golizadeh et al. 2007, Gorji et al. 2008, Aghdam et al. 2009b, Zahiri et al. 2010, Jalali et al. 2014).

\section{Performance Models}

Shi et al. (2011) proposed the following two Performance models to describe temperature-dependent development rate of arthropods:

$$
\begin{gathered}
R(T)=c\left(1-\mathrm{e}^{-K_{1}\left(T-T_{0}\right)}\right)\left(1-\mathrm{e}^{K_{2}\left(T-T_{\mathrm{U}}\right)}\right) \\
R(T)=m\left(T-T_{0}\right)\left(1-\mathrm{e}^{K_{2}\left(T-T_{\mathrm{U}}\right)}\right)
\end{gathered}
$$

where $R(T)$ is the development rate at temperature $T, T_{0}$ and $T_{\mathrm{U}}$ are lower and upper temperature thresholds, respectively, $c, m, K_{1}$, and $K_{2}$ are constant parameters. While equation 32 is actually a simplification of equation 31 , both models have very similar shapes when fitting development rate data (Wang et al. 2013) and both have been used in a number of studies (Wang et al. 2013, Park et al. 2014, Shi et al. 2016).

Equation 33 represents the Ratkowsky model which is the square root of Performance-2 (equation 32). This model was first used to describe the effect of temperature on the population growth rate of bacteria (Ratkowsky et al. 1983). Since then, this equation has been used in a number of insect thermal requirement studies
(Shi and Ge 2010, Sandhu et al. 2013, Shi et al. 2016, Ratkowsky and Reddy 2017). Shi et al. (2016) showed that among some nonlinear models (Briere, Lactin, Performance-2, Ratkowsky, and Beta), this model was best able to explain the relationship between temperature and development rate of some arthropods. This model is defined as follows:

$$
\sqrt{R(T)}=c\left(T-T_{0}\right)\left(1-\mathrm{e}^{K\left(T-T_{\mathrm{U}}\right)}\right)
$$

and all parameters of this equation are the same as for the other Performance models.

\section{Wang Model}

This model was built by Wang et al. (1982) as follows:

$$
R(T)=\frac{m\left[1-\exp \left(K_{1}\left(T-T_{0}\right)\right)\right]\left[1-\exp \left(K_{2}\left(T-T_{U}\right)\right)\right]}{1+\exp \left(-c\left(T-T_{0}\right)\right)}
$$

where $R(T)$ is the development rate at temperature $T, T_{0}$ and $T_{\mathrm{U}}$ are lower and upper temperature thresholds, respectively, and $c, m$, $K_{1}$, and $K_{2}$ are constant parameters. Equation 34 is analogous to the Performance-1 (equation 31) model and shows better flexibility when fitting observed data than Performance- 1 due to an additional denominator $1+\exp \left(-c\left(T-T_{0}\right)\right)$ (Shi et al. 2011). This equation has been used by researchers to describe the temperature-dependent development of a number of arthropods (Chen and Liu 2002, Shi and Ge 2010, Sandhu et al. 2013).

\section{Beta Model}

The Beta model was introduced by Yin et al. (1995) to describe the effect of temperature on the rate of crop development. Since then, this equation has been used to show the relationship between temperature and arthropod development (Shi et al. 2016). The Beta model is defined as follows:

$$
R(T)=r_{\mathrm{m}}\left(\frac{T_{\mathrm{U}}-T}{T_{\mathrm{U}}-T_{\mathrm{opt}}}\right)\left(\frac{T-T_{0}}{T_{\mathrm{opt}}-T_{0}}\right)^{\left(T_{\mathrm{opt}}-T_{0}\right) /\left(T_{\mathrm{U}}-T_{\mathrm{opt}}\right)}
$$

where $R(T)$ is development rate at temperature $T, r_{\mathrm{m}}$ represents the maximum development rate which occurs at optimal temperature $\left(T_{\text {opt }}\right)$, and $T_{0}$ and $T_{\mathrm{U}}$ are the lower and upper temperature thresholds, respectively.

\section{Criteria to Evaluate Model Performance}

As previously explained, there are several linear and nonlinear models that can be used to describe the relationship between temperature and arthropod development. Moreover, nonlinear models are more difficult to fit than linear ones as they require more preparation with the specification of the model and initial guesses for parameter values (Zahiri et al. 2010). Model selection should not be based solely on goodness-of-fit, but must also consider model complexity. A highly complex model can provide a good fit without necessarily bearing any interpretable relationship with the underlying process. Model selection based solely on the fit to observed data will result in the choice of an unnecessarily complex model that over-fits the data, and thus generalizes poorly (Fig. 6) (Schwarz 1978). The effect of over-fitting must be properly offset by model selection methods.

However, different criteria have been used to assess the performance of mathematical models, as follows. 


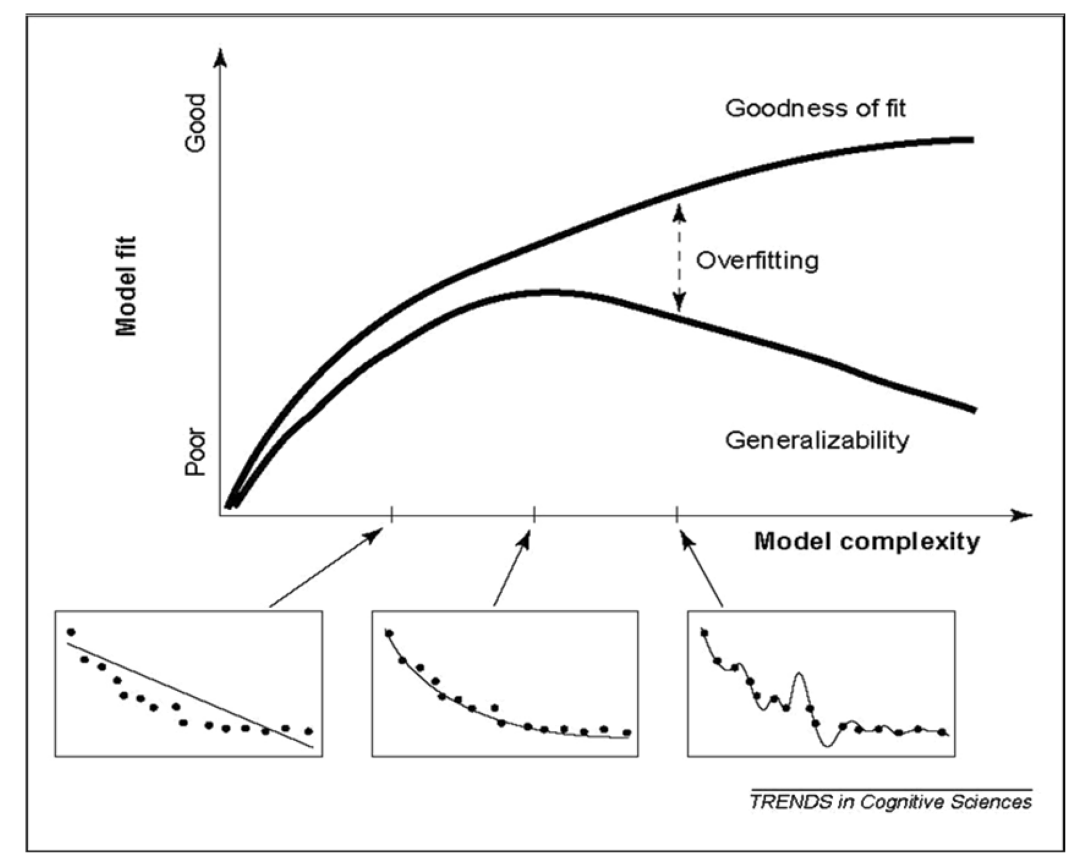

Fig. 6. Relationship between goodness-of-fit and generalizability as a function of model complexity. The $y$-axis represents any fit index, where a larger value indicates a better fit (e.g., percent variance accounted for). The three smaller graphs along the x-axis show how fit improves as complexity increases. In the left graph, the model (represented by the line) is not complex enough to match the complexity of the data (dots). The two are well matched in complexity in the middle graph, which is why this occurs at the peak of the generalizability function. In the right graph, the model is more complex than the data, fitting random error. It has better goodness-of-fit, but is overfitting the data (Schwarz 1978).

Coefficient of Determination $\left(\mathbf{R}^{2}\right)$ and Adjusted $\mathbf{R}^{2}$ adj

By definition, the coefficient of determination $\left(R^{2}\right)$ is a number which indicates the proportion of the variance in the dependent variable that is predictable from the independent variable. The $R^{2}$ value is not suitable for determining the best model among models with different numbers of parameters because the models with more parameters always have a better fit; in other words, this criterion is dependent on the number of model parameters. Hence, to compare the models with different number of parameters, using an adjusted $R^{2}\left(R_{\text {adj }}^{2}\right)$ is recommended. The $R_{\text {adj }}^{2}$ is calculated as follows:

$$
R_{\text {adj }}^{2}=1-\left(\frac{n-1}{n-p}\right)\left(1-R^{2}\right)
$$

where $n$ is the number of observations (sample size), $p$ is the number of model parameters, and $R^{2}$ is the coefficient of determination. It is clear that the higher value of $R^{2}$ and $R_{\text {adj }}^{2}$ indicate a better fit.

\section{Residual Sum of Square (RSS or SSE)}

Residual sum of square, also known as the sum of squared error (SSE), is defined as the sum of squares of deviations predicted from actual empirical values of data. $R^{2}$ adj and RSS are commonly used for model evaluation, where a lower value of RSS indicates a better fit.

\section{Root Mean Square Error (RMSE)}

The root mean square error is the standard deviation of the residuals. To clarify, this is a frequently used measure of the differences between values predicted by a model or an estimator and the values actually observed. Some authors believe that in models with same number of parameters, the RMSE should be given priority to relative to the others (Ratkowsky and Reddy 2017, Shi et al. 2017b).

\section{Akaike Information Criterion (AIC) and Corrected AIC (AICc)}

This criterion is the function that minimizes the loss of information (Akaike 1974). It is a good criterion for comparing models due to its independence from number of parameters. The AIC is calculated using the following equation (37):

$$
\mathrm{AIC}=n \ln \left(\frac{\mathrm{SSE}}{n}\right)+2 p
$$

where $n$ is the number of observations, $p$ is the number of model parameters including the intercept, and SSE is the sum of the squared error (residual sum of square).

Although AIC is supposed to result in the selection of a parsimonious model, this will not always be the case. In fact, if given a chance, AIC will prefer a model with $p$ parameters to any other model. Thus, in extreme circumstances, AIC can severely violate the principle of parsimony. The failure of AIC to select an adequately parsimonious model can be a problem whenever the number of parameters in the model under consideration is more than (roughly) $30 \%$ of the sample size. It could be argued that a good model selection criterion should work even if the user tries a 'bad' (e.g., over-parametrized) model. If the model is bad, the criterion should be able to detect this. In this regard, AIC fails to remove this deficiency. Hurvich and Tsai (1989) introduced a corrected version, $\mathrm{AIC}_{\mathrm{c}}$, defined by the following equation:

$$
\mathrm{AIC}_{c}=\mathrm{AIC}+\frac{2 p(n+1)}{n-p-1}
$$

where $p$ and $n$ are the same as in equation 37 . 
Bayesian Information Criterion (BIC) or Schwarz Criterion The Bayesian information criterion (BIC) or Schwarz criterion (also SBC, SBIC) is a criterion for model selection among a class of parametric models with different numbers of parameters. Choosing a model to optimize BIC is a form of regularization. When estimating model parameters using maximum likelihood estimation, it is possible to increase the likelihood by adding additional parameters, which may result in overfitting. The BIC resolves this problem by introducing a penalty term for the number of parameters in the model. The BIC was developed by Schwarz (1978), who gave a Bayesian argument for adopting it. It is very closely related to the AIC. In BIC, the penalty for use of additional parameters is greater than that of the AIC. The BIC equation is as follows (equation 39):

$$
\mathrm{BIC}=-2 \ln L_{\max }+p \ln n
$$

where $n$ is the number of observations, $p$ is the number of model parameters including the intercept, and $L_{\max }$ is the maximum likelihood achieved by the model.

\section{A Facilitated Approach for Thermal Modeling}

\section{Why a Facilitated Approach?}

As mentioned earlier, there are several commonly used (linear and nonlinear) models for estimating insect thermal requirements. Since the linear models do not provide either the optimal temperature $\left(T_{\text {opt }}\right)$ or the upper temperature threshold $\left(T_{U}\right)$, estimation of these crucial temperatures has been performed by a variety of nonlinear models. The nonlinear models are more complex than linear ones and this approach in general has the following issues:

- Some of these models are old and hence, access to their original source can be difficult. This issue causes some researchers to use these models in their papers incorrectly.

- Although there are some packages in R software (e.g., 'devRate' and 'IPEC') to quantify the relationship between development rate and temperature, collection and calculation of all widely used models is not easy and researchers must be familiar with some software that is not user-friendly (e.g., SAS, R, etc.).
- In calculating a model's parameters, the initial values (a set of starting point values belonging to the variables in an equation that have one or more arbitrary constants) that are entered into software programs by researchers can affect the final results.

- Most problems are related to the selection of the best model. Different models have different accuracy in predicting arthropod development rate and researchers thus have to evaluate many models to select the best for their situation. As previously mentioned, in selecting the best model several criteria have to be appropriately applied.

- Plotting of the models results for reports or papers can be time consuming.

\section{The ArthroThermoModel Software}

The above-mentioned problems motivated us to design a suitable statistical package that would minimize the complexity of the nonlinear models and facilitate the selection of the best model. To design this package, MATLAB software (MATLAB 2014, version 8.3.0.532) was used. This software has a high proficiency in statistical analysis and graphical drawings. Moreover, the main trait of this software is its programmability, making it appropriate for this purpose.

The name ArthroThermoModel software (in abbreviation ATM) is derived from three words, Arthropod, Thermal, and Models. This user-friendly software is executable on any computer with MATLAB 2014 or 2015 . Some features of this software are: 1) its small size (approximately $6 \mathrm{~kb}$ ), making it easy to download, 2) its userfriendly design, where a user merely enters the address of data that are stored in excel files, 3 ) its high speed in processing and computing models (less than $2 \mathrm{~min}$ for all linear and nonlinear models presented in this paper), and finally 4) the feature where the software provides all the parameters for all models, graphs for all nonlinear models and useful criteria (SSE, $R^{2}, R^{2}$ adj, and AIC) for evaluating model performance. To evaluate the ATM software, the raw data from Zahiri et al. (2010) were re-analyzed using all available models (Tables 2 and 3). The differences between the output of the ATM software and the results of Zahiri et al. (2010) regarding the Ikemoto model (Table 2) are due to using OLS method by Zahiri et al. (2010), whereas ATM uses RMA method for this model (Ikemoto and Takai 2000). Some differences in Table 3 may be due to the different initial values used in the ATM software.

Table 2. Comparison of lower temperature threshold $\left(T_{0}\right)$ and thermal constant $(K)$ of immature stages of $H$. postica estimated by two linear models between Zahiri et al. (2010) and ATM software

\begin{tabular}{|c|c|c|c|c|c|c|c|c|}
\hline \multirow[t]{2}{*}{ Stage } & \multicolumn{4}{|c|}{ Ordinary } & \multicolumn{4}{|c|}{ Ikemoto } \\
\hline & $K(\mathrm{DD})$ & $T_{0}\left({ }^{\circ} \mathrm{C}\right)$ & $R_{\text {adj }}^{2}$ & $P$-value & $K(\mathrm{DD})$ & $T_{0}\left({ }^{\circ} \mathrm{C}\right)$ & $R_{\text {adj }}^{2}$ & $P$-value \\
\hline Egg & $100.24(100.24)$ & $10.63(10.63)$ & $0.97(0.97)$ & $<0.01(<0.01)$ & $98.51(112.09)$ & $10.99(9.64)$ & $0.99(0.99)$ & $<0.01(<0.01)$ \\
\hline Larva I & $33.18(33.18)$ & $10.55(10.55)$ & $0.95(0.95)$ & $<0.01(<0.01)$ & $32.79(37.41)$ & $10.94(9.48)$ & $0.99(0.98)$ & $<0.01(<0.01)$ \\
\hline Larva II & $30.46(30.46)$ & $11.78(11.78)$ & $0.94(0.94)$ & $<0.01 \quad(<0.01)$ & $24.83(38.05)$ & $14.81(9.69)$ & $0.98(0.95)$ & $<0.01(<0.01)$ \\
\hline Larva III & $41.86(41.86)$ & $10.25(10.25)$ & $0.95(0.95)$ & $<0.01(<0.01)$ & $39.18(45.75)$ & $10.80(9.19)$ & $0.99(0.97)$ & $<0.01(<0.01)$ \\
\hline Larva IV & $44.01(44.01)$ & $12.15(12.15)$ & $0.94(0.94)$ & $<0.01(<0.01)$ & $45.61(59.96)$ & $11.84(8.70)$ & $0.98(0.96)$ & $<0.01(<0.01)$ \\
\hline Prepupa & $34.75(34.75)$ & $10.39(10.39)$ & $0.96(0.96)$ & $<0.01(<0.01)$ & $32.56(38.37)$ & $10.92(9.31)$ & $0.99(0.98)$ & $<0.01(<0.01)$ \\
\hline Pupa & $59.87(59.87)$ & $11.78(11.78)$ & $0.98(0.98)$ & $<0.01(<0.01)$ & $64.63(72.56)$ & $11.08(9.67)$ & $0.99(0.98)$ & $<0.01(<0.01)$ \\
\hline Immature & $313.85(313.85)$ & $11.61(11.61)$ & $0.98(0.98)$ & $<0.01(<0.01)$ & $335.84(382.70)$ & $10.99(9.53)$ & $0.99(0.98)$ & $<0.01(<0.01)$ \\
\hline
\end{tabular}

The raw data of Zahiri et al. (2010) were taken and re-analyzed with the ArthroThermoModel software. Numbers in parentheses indicate values which were calculated using the ArthroThermoModel software. 
Table 3. Comparison of calculated goodness-of-fit of some nonlinear models fitted to the development rate of egg, larva, and total immature stages of $H$. postica between Zahiri et al. (2010) and ATM software

\begin{tabular}{|c|c|c|c|c|c|c|}
\hline \multirow[t]{2}{*}{ Model } & \multicolumn{2}{|r|}{ Egg } & \multicolumn{2}{|c|}{ Larva } & \multicolumn{2}{|c|}{ Immature } \\
\hline & SSE & AIC & SSE & AIC & SSE & AIC \\
\hline Pradhan-Taylor & $0.4426(0.4426)$ & $-8505.88(-8505.88)$ & $0.1098(0.1098)$ & $-7794.12(-7794.12)$ & $0.0103(0.0103)$ & $-8378.48(-8378.49)$ \\
\hline Davidson (Logistic) & $0.7594(0.7594)$ & $-7917.35(-7917.35)$ & $0.1885(0.1885)$ & $-7324.66(-7324.66)$ & $0.0162(0.0162)$ & $-8038.61(-8038.61)$ \\
\hline Logan-6 & $0.1270(0.1270)$ & $-9864.73(-9864.73)$ & $0.0329(0.0330)$ & $-8838.31(-8838.30)$ & $0.0034(0.0034)$ & $-9213.44(-9212.60)$ \\
\hline Logan-10 & $0.0968(0.0968)$ & $-10158.53(-10158.53)$ & $0.0324(0.0324)$ & $-8849.79(-8849.79)$ & $0.0030(0.0030)$ & $-9287.26(-9287.27)$ \\
\hline Hilbert and Logan & $0.1087(0.1007)$ & $-10032.58(-10115.27)$ & $0.0449(0.0329)$ & $-8567.01(-8837.90)$ & $0.0029(0.0030)$ & $-9310.85(-9310.64)$ \\
\hline Lactin-1 & $0.1295(0.1295)$ & $-9845.78(-9845.78)$ & $0.0330(0.0330)$ & $-8840.12(-8840.11)$ & $0.0034(0.0034)$ & $-9215.51(-9212.55)$ \\
\hline Lactin-2 & $0.1181(0.1181)$ & $-9944.12(-9944.12)$ & $0.0499(0.0499)$ & $-8478.31(-8478.31)$ & $0.0056(0.0056)$ & $-8829.35(-8829.35)$ \\
\hline Analytis-1 & $0.0996(0.0996)$ & $-10127.27(-10127.27)$ & $0.0322(0.0322)$ & $-8856.36(-8856.06)$ & $0.0030(0.0030)$ & $-9296.50(-9296.16)$ \\
\hline Analytis-2 & $0.0957(0.4491)$ & $-10171.37(-8485.85)$ & $0.0322(0.1176)$ & $-8856.36(-7730.66)$ & $0.0030(0.0116)$ & $-9296.50(-8288.12)$ \\
\hline Analytis-3 & $0.0996(-)$ & $10127.28(-)$ & $0.0329(0.0363)$ & $-8837.43(-8752.14)$ & $0.0030(0.0033)$ & $-9295.55(-9226.42)$ \\
\hline Analytis-1/Allahyari & $0.0993(0.0993)$ & $-10131.28(-10131.28)$ & $0.0320(0.0324)$ & $-8862.50(-8851.66)$ & $0.0029(0.0029)$ & $-9312.52(-9312.52)$ \\
\hline Analytis-3/Kontodimas & $0.4581(0.4581)$ & $-8468.30(-8468.30)$ & $0.1256(0.1256)$ & $-7677.34(-7677.34)$ & $0.0132(0.0132)$ & $-8192.28(-8192.28)$ \\
\hline Briere-1 & $0.3039(0.3039)$ & $-8915.68(-8915.68)$ & $0.0893(0.0893)$ & $-7973.56(-7973.56)$ & $0.0105(0.0105)$ & $-8365.83(-8365.83)$ \\
\hline Briere-2 & $0.0994(-)$ & $-10131.57(-)$ & $0.0429(0.0481)$ & $-8609.09(-8510.35)$ & $0.0039(0.0048)$ & $-9097.94(-8952.92)$ \\
\hline Janisch/Kontodimas & $0.2042(0.1280)$ & $-9347.19(-9856.09)$ & $0.0430(0.0336)$ & $-8607.72(-8822.19)$ & $0.0050(0.0036)$ & $-8909.00(-9172.84)$ \\
\hline Janisch/Rochat & $0.2042(0.2042)$ & $-9347.19(-9347.19)$ & $0.0430(0.0430)$ & $-8607.72(-8607.72)$ & $0.0050(0.0051)$ & $-8909.00(-8909.00)$ \\
\hline Sharpe and DeMichele & $0.1938(4.4648)$ & $-9398.07(-5980.51)$ & $0.0414(0.4362)$ & $-8632.90(-6589.84)$ & $0.0048(0.0048)$ & $-8939.49(-8941.47)$ \\
\hline $\begin{array}{l}\text { Sharpe and DeMichele/ } \\
\text { Schoolfield }\end{array}$ & $0.1937(0.2772)$ & $-9398.46(-9010.00)$ & $0.0414(0.4009)$ & $-8633.04(-6663.04)$ & $0.0048(0.0048)$ & $-8939.62(-8938.27)$ \\
\hline
\end{tabular}

The raw data of Zahiri et al. (2010) were taken and re-analyzed with the ArthroThermoModel software. Numbers in parentheses indicate values which were calculated using the ArthroThermoModel software. (-) means entered data did not fit with this model.

\section{Acknowledgments}

The support of this study by the Department of Entomology, Tarbiat Modares University, is greatly appreciated. The ATM software and its manual can be freely accessed by contacting the corresponding author (fathi@modares.ac.ir). Users are requested to cite this article in their publications.

\section{References Cited}

Aghdam, H. R., Y. Fathipour, and D. Kontodimas. 2011. Evaluation of nonlinear models to describe development and fertility of codling moth at constant temperatures. Entomol. Hell. 20: 3-16.

Aghdam, H. R., Y. Fathipour, G. Radjabi, and M. Rezapanah. 2009a. Temperature-dependent development and temperature thresholds of codling moth (Lepidoptera: Tortricidae) in Iran. Environ. Entomol. 38: 885-895.

Aghdam, H. R., Y. Fathipour, D. C. Kontodimas, G. Radjabi, and M. Rezapanah. 2009b. Age-specific life table parameters and survivorship of an Iranian population of the codling moth (Lepidoptera: Tortricidae) at different constant temperatures. Ann. Entomol. Soc. Am. 102: 233-240.

Akaike, H. 1974. A new look at the statistical model identification. IEEE Trans. Autom. Control 19: 716-723.

Allahyari, H. 2005. Decision making with degree-day in control program of Colorado potato beetle. Ph.D. dissertation, University of Tehran Tehran, Iran.

Allen, J. C. 1976. A modified sine wave method for calculating degree days. Environ. Entomol. 5: 388-396.

Analytis, S. 1977. Uber die Relation zwischen biologischer Entwicklung und Temperatur bei phytopathogenen Pilzen. J. Phytopathol. 90: 64-76.

Analytis, S. 1980. Obtaining of sub-models for modeling the entire life cycle of a pathogen. J. Plant Dis. Protec. 87: 371-382.

Analytis, S. 1981. Relationship between temperature and development times in phytopathogenic fungus and in plant pests: a mathematical model. Agr. Res. (Athens) 5: 133-159.

Andrewartha, H. G., and L. C. Birch. 1954. The distribution and abundance of animals. University of Chicago Press, Chicago.

Arbab, A., and M. R. Mcneill. 2011. Determining suitability of thermal development models to estimate temperature parameters for embryonic development of Sitona lepidus Gyll. (Coleoptera: Curculionidae). J. Pest Sci. 84: 303-311.

Arbab, A., D. C. Kontodimas, and A. Sahragard. 2006. Estimating development of Aphis pomi (DeGeer) (Homoptera: Aphididae) using linear and nonlinear models. Environ. Entomol. 35: 1208-1215.

Arbab, A., D. C. Kontodimas, and M. R. McNeill. 2008. Modeling embryo development of Sitona discoideus Gyllenhal (Coleoptera: Curculionidae) under constant temperature. Environ. Entomol. 37: 1381-1388.

Arbab, A., N. Heydari, and H. Pakyari. 2016. Temperature-dependent development of pale damsel bug, Nabis capsiformis Geramer (Hemiptera: Nabidae) using linear and non-linear models. Crop Protect. 89: 248-254.

Arnold, C. Y. 1960. Maximum-minimum temperatures as a basis for computing heat units. Proc. Am. Soc. Hort. Sci. 76: 682-692.

Atkinson, P. R. 1977. Preliminary analysis of a field population of citrus red scale, Aonidiella aurantii (Maskell), and the measurement and expression of stage duration and reproduction for life tables. Bull. Entomol. Res. 67: $65-87$.

Barzegar, S., A. A. Zamani, S. Abbasi, R. V. Shooshtari, and N. S. Farsani. 2016. Temperature-dependent development modeling of the phorid fly Megaselia halterata (Wood) (Diptera: Phoridae). Neotrop. Entomol. 45: 507-517.

Baskerville, G., and P. Emin. 1969. Rapid estimation of heat accumulation from maximum and minimum temperatures. Ecology 50: 514-517.

Briere, J.-F., P. Pracros, A.-Y. Le Roux, and J.-S. Pierre. 1999. A novel rate model of temperature-dependent development for arthropods. Environ. Entomol. 28: 22-29.

Bryant, S. R., C. D. Thomas, and J. S. Bale. 2002. The influence of thermal ecology on the distribution of three nymphalid butterflies. J. Appl. Ecol. 39: 43-55.

Campbell, A., B. D. Frazer, N. Gilbert, A. P. Gutierrez, and M. Mackauer. 1974. Temperature requirements of some aphids and their parasites. J. Appl. Ecol. 11: 431-438.

Chen, F., and S. Liu. 2002. Development rate of Plutella xylostella L. (Lepidoptera: Plutelli dae) under constant and variable temperatures. Acta Ecol. Sinica 23: 688-694.

Davidson, J. 1942. On the speed of development of insect eggs at constant temperatures. Aust. J. Exp. Biol. Med. Sci. 20: 233-239.

Davidson, J. 1944. On the relationship between temperature and rate of development of insects at constant temperatures. J. Anim. Ecol. 13: 26-38. 
De Clerq, P., and D. Degheele. 1992. Development and survival of Podisus maculiventris (Say) and Podisus sagitta (Fab.) (Het.: Pentatomidae) at various constant temperatures. Can. Entomol. 124: 125-133.

Dent, D. 2000. Insect pest management, University Press, Cambridge, United Kingdom.

Fatzinger, C. W., and W. N. Dixon. 1996. Degree-day models for predicting levels of attack by slash pine flower thrips (Thysanoptera: Phlaeothripidae) and the phenology of female strobilus development on slash pine. Environ. Entomol. 25: 727-735.

Frazer, B., and R. McGregor. 1992. Temperature-dependent survival and hatching rate of eggs of seven species of Coccinellidae. Can. Entomol. 124: 305-312.

Ganjisaffar, F., Y. Fathipour, and K. Kamali. 2011a. Effect of temperature on prey consumption of Typhlodromus bagdasarjani (Acari: Phytoseiidae) on Tetranychus urticae (Acari: Tetranychidae). Int. J. Acarol. 37: 556-560.

Ganjisaffar, F., Y. Fathipour, and K. Kamali. 2011b. Temperature-dependent development and life table parameters of Typhlodromus bagdasarjani (Phytoseiidae) fed on two-spotted spider mite. Exp. Appl. Acarol. 55: 259-272.

Glenn, P. 1922. Relation of temperature to development of the codling-moth J. Econ. Entomol. 15: 193-199.

Golizadeh, A., and M. P. Zalucki. 2012. Estimating temperature-dependent developmental rates of potato tuberworm, Phthorimaea operculella (Lepidoptera: Gelechiidae). Insect Sci. 19: 609-620.

Golizadeh, A., K. Kamali, Y. Fathipour, and H. Abbasipour. 2007. Temperature-dependent development of diamondback moth, Plutella xylostella (Lepidoptera: Plutellidae) on two brassicaceous host plants. Insect Sci. 14: 309-316.

Golizadeh, A., K. Kamali, Y. Fathipour, and H. Abbasipour. 2008. Life table and temperature-dependent development of Diadegma anurum (Hymenoptera: Ichneumonidae) on its host Plutella xylostella (Lepidoptera: Plutellidae). Environ. Entomol. 37: 38-44.

Gorji, M. K., K. Kamali, Y. Fathipour, and H. R. Aghdam. 2008. Temperaturedependent development of Phytoseius plumifer (Acari: Phytoseiidae) on Tetranychus urticae (Acari: Tetranychidae). Syst. Appl. Acarol. 13 172-181.

Grout, T. G., and K. C. Stoltz. 2007. Developmental rates at constant temperatures of three economically important Ceratitis spp. (Diptera: Tephritidae) from southern Africa. Environ. Entomol. 36: 1310-1317.

Haghani, M., Y. Fathipour, A. A. Talebi, and V. Baniameri. 2007a. Thermal requirement and development of Liriomyza sativae (Diptera: Agromyzidae) on cucumber. J. Econ. Entomol. 100: 350-356.

Haghani, M., Y. Fathipour, A. A. Talebi, and V. Baniameri. 2007b. Temperature-dependent development of Diglyphus isaea (Hymenoptera: Eulophidae) on Liriomyza sativae (Diptera: Agromyzidae) on cucumber. J. Pest Sci. 80: 71-77.

Harcourt, D., and J. Yee. 1982. Polynomial algorithm for predicting the duration of insect life stages. Environ. Entomol. 11: 581-584.

Hilbert, D., and J. Logan. 1983. Empirical model of nymphal development for the migratory grasshopper, Melanoplus sanguinipes (Orthoptera: Acrididae). Environ. Entomol. 12: 1-5.

Howell, J. F., and L. G. Neven. 2000. Physiological development time and zero development temperature of the codling moth (Lepidoptera: Tortricidae). Environ. Entomol. 29: 766-772.

Hurvich, C. M., and C.-L. Tsai. 1989. Regression and time series model selection in small samples. Biometrika 76: 297-307.

Ikemoto, T. 2005. Intrinsic optimum temperature for development of insects and mites. Environ. Entomol. 34: 1377-1387.

Ikemoto, T. 2008. Tropical malaria does not mean hot environments. J. Med. Entomol. 45: 963-969

Ikemoto, T., and K. Takai. 2000. A new linearized formula for the law of total effective temperature and the evaluation of line-fitting methods with both variables subject to error. Environ. Entomol. 29: 671-682.

Ikemoto, T., I. Kurahashi, and P. J. Shi. 2013. Confidence interval of intrinsic optimum temperature estimated using thermodynamic SSI model. Insect Sci. 20: 420-428

Jafari, S., Y. Fathipour, and F. Faraji. 2012a. The influence of temperature on the functional response and prey consumption of Neoseiulus barkeri
(Acari: Phytoseiidae) on Tetranychus urticae (Acari: Tetranychidae). J. Entomol. Soc. Iran 31: 39-52.

Jafari, S., Y. Fathipour, and F. Faraji. 2012b. Temperature-dependent development of Neoseiulus barkeri (Acari: Phytoseiidae) on Tetranychus urticae (Acari: Tetranychidae) at seven constant temperatures. Insect Sci. 19 220-228.

Jafari, S., Y. Fathipour, F. Faraji, and M. Bagheri. 2010. Demographic response to constant temperatures in Neoseiulus barkeri (Phytoseiidae) fed on Tetranychus urticae (Tetranychidae). Syst. Appl. Acarol. 15: 83-99.

Jalali, M. A., L. Tirry, A. Arbab, and P. De Clercq. 2010. Temperaturedependent development of the two-spotted ladybeetle, Adalia bipunctata on the green peach aphid, Myzus persicae, and a factitious food under constant temperatures. J. Insect Sci. 10: 124

Jalali, M. A., M. R. Mehrnejad, and D. C. Kontodimas. 2014. Temperaturedependent development of the five psyllophagous ladybird predators of Agonoscena pistaciae (Hemiptera: Psyllidae). Ann. Entomol. Soc. Am. 107: 445-452.

Janisch, E. 1932. The influence of temperature on the life-history of insects. T. Roy. Entomolo. Soc. London 80: 137-168.

Johnson, D., R. Bessin, and L. Townsend. 1998. Predicting insect development using degree days. Entomology Fact Sheet No. 123. University of Kentucky.

Karimi-Malati, A., Y. Fathipour, and A. A. Talebi. 2014. Development response of Spodoptera exigua to eight constant temperatures: linear and nonlinear modeling. J. Asia-Pac. Entomol. 17: 349-354.

Kheradmand, K., K. Kamali, Y. Fathipour, E. M. Goltapeh, and A. Camerik. 2006. Biology and life table parameters of the mushroom pest, Pediculaster fletchmanni (Acari: Siteroptidae), at three constant temperatures. Insect Sci. 13: 375-380.

Kheradmand, K., K. Kamali, Y. Fathipour, E. M. Goltapeh, and E. A. Ueckermann. 2007. Thermal requirement for development of Sancassania rodionovi (Acari: Acaridae) on mushrooms. J. Econ. Entomol. 100: 1098-1103.

Kim, D.-S., J.-H. Lee, and M.-S. Yiem. 2001. Temperature-dependent development of Carposina sasakii (Lepidoptera: Carposinidae) and its stage emergence models. Environ. Entomol. 30: 298-305.

Kontodimas, D. C., P. A. Eliopoulos, G. J. Stathas, and L. P. Economou. 2004 Comparative temperature-dependent development of Nephus includen (Kirsch) and Nephus bisignatus (Boheman) (Coleoptera: Coccinellidae) preying on Planococcus citri (Risso) (Homoptera: Pseudococcidae): evaluation of a linear and various nonlinear models using specific criteria. Environ. Entomol. 33: 1-11.

Kouhjani-Gorji, M., Y. Fathipour, and K. Kamali. 2012. Life table parameters of Phytoseius plumifer (Phytoseiidae) fed on two-spotted spider mite at different constant temperatures. Int. J. Acarol. 38: 377-385.

Lactin, D. J., N. Holliday, D. Johnson, and R. Craigen. 1995. Improved rate model of temperature-dependent development by arthropods. Environ. Entomol. 24: 68-75.

Lindsey, A. A., and J. E. Newman. 1956. Use of official wather data in spring time: temperature analysis of an Indiana phenological record. Ecology 37: 812-823.

Logan, J. D., W. Wolesensky, and A. Joern. 2006. Temperature-dependent phenology and predation in arthropod systems. Ecol. Model. 196: 471-482.

Logan, J., D. Wollkind, S. Hoyt, and L. Tanigoshi. 1976. An analytic model for description of temperature dependent rate phenomena in arthropods. Environ. Entomol. 5: 1133-1140.

Lopez-Arroyo, J. I., C. A. Tauber, and M. J. Tauber. 1999. Comparative life histories of the predators Ceraeochrysa cincta, C. cubana, and C. smithi (Neuroptera: Chrysopidae). Ann. Entomol. Soc. Am. 92: 208-217.

Ludwig, D. 1928. The effects of temperature on the development of an insect (Popillia japonica Newman). Physiol. Zool. 1: 358-389.

Medeiros, R. S., F. S. Ramalho, J. E. Serrao, and J. C. Zanuncio. 2004 Estimative of Podisus nigrispinus (Dallas) (Heteroptera: Pentatomidae development time with non linear models. Neot. Entomol. 33: 141-148.

Nechols, J. R., M. J. Tauber, C. A. Tauber, and S. Masaki. 1999. Adaptations to hazardous seasonal conditions: dormancy, migration, and polyphenism, pp. 159-200. In C. B. Huffaker and A. P. Guttierez (eds.), Ecological Entomology, 2nd ed. Wiley, New York. 
Pakyari, H., Y. Fathipour, and A. Enkegaard. 2011a. Effect of temperature on life table parameters of predatory thrips Scolothrips longicornis (Thysanoptera: Thripidae) fed on twospotted spider mites (Acari: Tetranychidae). J. Econ. Entomol. 104: 799-805.

Pakyari, H., Y. Fathipour, and A. Enkegaard. 2011b. Estimating development and temperature thresholds of Scolothrips longicornis (Thysanoptera: Thripidae) on eggs of two-spotted spider mite using linear and nonlinear models. J. Pest Sci. 84: 153-163.

Pakyari, H., Y. Fathipour, M. Rezapanah, and K. Kamali. 2009. Temperaturedependent functional response of Scolothrips longicornis (Thysanoptera: Thripidae) preying on Tetranychus urticae. J. Asia-Pac. Entomol. 12: 23-26.

Park, H. H., J. J. Ahn, and C.-G. Park. 2014. Temperature-dependent development of Cnaphalocrocis medinalis Guenee (Lepidoptera: Pyralidae) and their validation in semi-field condition. J. Asia-Pac. Entomol. 17: 83-91.

Pradhan, S. 1945. Insect population studies. II. Rate of insect development under variable temperatures of the field. Proc. Nat. Inst. Sci. India. 11: 74-80.

Pruess, K. P. 1983. Day-degree methods for pest management. Environ Entomol. 12: 613-619.

Ratkowsky, D. A., and G. V. P. Reddy. 2017. Empirical model with excellent statistical properties for describing temperature-dependent developmental rates of insects and mites. Ann. Entomol. Soc. Am. 110: 302-309.

Ratkowsky, D. A., R. Lowry, T. McMeekin, A. Stokes, and R. Chandler. 1983 Model for bacterial culture growth rate throughout the entire biokinetic temperature range. J. Bacteriol. 154: 1222-1226.

Rochat, J., and A. P. Gutierrez. 2001. Weather-mediated regulation of olive scale by two parasitoids. J. Anim. Ecol. 70: 476-490.

Roltsch, W. J., F. G. Zalom, A. J. Strawn, J. F. Strand, and M. J. Pitcairn. 1999 Evaluation of several degree-day estimation methods in California climates. Int. J. Biometeorol. 42: 169-176.

Roy, M., J. Brodeur, and C. Cloutier. 2002. Relationship between temperature and developmental rate of Stethorus punctillum (Coleoptera: Coccinellidae) and its prey Tetranychus mcdanieli (Acarina: Tetranychidae). Environ. Entomol. 31: 177-187.

Sandehson, D. E. 1910. The relation of temperature to the growth of insects. J. Econ. Entomol. 3: 113-140.

Sandhu, H. S., G. S. Nuessly, S. E. Webb, R. H. Cherry, and R. A. Gilbert. 2013. Temperature-dependent reproductive and life table parameters of Elasmopalpus lignosellus (Lepidoptera: Pyralidae) on sugarcane. Fla. Entomol. 96: 380-390.

Schoolfield, R., P. Sharpe, and C. Magnuson. 1981. Non-linear regression of biological temperature-dependent rate models based on absolute reactionrate theory. J. Theor. Biol. 88: 719-731.

Schwarz, G. 1978. Estimating the dimension of a model. Ann. Stat. 6: 461-464

Sevacherian, V., V. Stern, and A. Mueller. 1977. Heat accumulation for timing Lygus control measures in a safflower-cotton complex. J. Econ. Entomol. 70: 399-402.

Sharpe, P. J., and D. W. DeMichele. 1977. Reaction kinetics of poikilotherm development. J. Theor. Biol. 64: 649-670.

Shi, P. J., and F. Ge. 2010. A comparison of different thermal performance functions describing temperature-dependent development rates. J. Therm. Biol. 35: 225-231.

Shi, P. J., F. Ge, Y. Sun, and C. Chen. 2011. A simple model for describing the effect of temperature on insect developmental rate. J. Asia-Pac. Entomol. 14: $15-20$.

Shi, P. J., G. V. Reddy, L. Chen, and F. Ge. 2016. Comparison of thermal performance equations in describing temperature-dependent developmental rates of insects:(I) empirical models. Ann. Entomol. Soc. Am. 109 211-215.

Shi, P. J., M. Fan, and G.V.P. Reddy. 2017a. Comparison of thermal performance equations in describing temperature-dependent developmental rates of insects: (III) Phenological applications. Ann. Entomol. Soc. Am. https://doi.org/10.1093/aesa/sax063.

Shi, P. J., G. V. Reddy, L. Chen, and F. Ge. 2017b. Comparison of thermal performance equations in describing temperature-dependent developmental rates of insects:(II) two thermodynamic models. Ann. Entomol. Soc. Am. 110: 113-120.

Stinner, R., A. Gutierrez, and G. Butler. 1974. An algorithm for temperaturedependent growth rate simulation. Can. Entomol. 106: 519-524.

Taghizadeh, R., Y. Fathipour, and K. Kamali. 2008. Temperature-dependent development of acarophagous ladybird, Stethorus gilvifrons (Mulsant) (Coleoptera: Coccinellidae). J. Asia-Pac. Entomol. 11: 145-148.

Taylor, F. 1981. Ecology and evolution of physiological time in insects. Am. Nat. 117: 1-23.

Tazerouni, Z., A. A. Talebi, and E. Rakhshani. 2013. Temperature thresholds and thermal requirements for development of Iranian Diuraphis noxia population (Hemiptera: Aphididae) on wheat. Zool. Ecol. 23: 323-329.

Tobin, P. C., S. Nagarkatti, and M. C. Saunders. 2001. Modeling development in grape berry moth (Lepidoptera: Tortricidae). Environ. Entomol. 30: 692-699.

Trudgill, D., A. Honek, D. Li, and N. Straalen. 2005. Thermal time-concepts and utility. Ann. Appl. Biol. 146: 1-14.

Wagner, T. L., H. Wu, P. J. Sharpe, R. M. Schoolfield, and R. N. Coulson. 1984. Modeling insect development rates: a literature review and application of a biophysical model. Ann. Entomol. Soc. Am. 77: 208-220.

Walgama, R. S., and M. P. Zalucki. 2006. Evaluation of different models to describe egg and pupal development of Xyleborus fornicatus Eichh. (Coleoptera: Scolytidae), the shot-hole borer of tea in Sri Lanka. Insect Sci. 13: 109-118.

Wang, J. Y. 1960. A critique of the heat unit approach to plant response studies. Ecology 41: 785-790.

Wang, L., P. Shi, C. Chen, and F. Xue. 2013. Effect of temperature on the development of Laodelphax striatellus (Homoptera: Delphacidae). J. Econ. Entomol. 106: 107-114.

Wang, R., Z. Lan, and Y. Ding. 1982. Studies on mathematical models of the relationship between insect development and temperature. Acta Ecol. Sinica 2: 47-57.

Worner, S. P. 1992. Performance of phenological models under variable temperature regimes: consequences of the Kaufmann or rate summation effect. Environ. Entomol. 21: 689-699.

Worner, S. P. 2008. Bioclimatic models in entomology, pp. 476-481. In: Capinera, J. L. (ed.) Encyclopedia of Entomology. Springer, Dordrecht, the Netherlands.

Yin, X., M. J. Kropff, G. McLaren, and R. M. Visperas. 1995. A nonlinear model for crop development as a function of temperature. Agric. For. Meteorol. 77: 1-16.

Young, L. J., and J. H. Young. 1998. Statistical ecology: a population perspective. Kluwer Academic Publishers, Boston, MA.

Zahiri, B., Y. Fathipour, M. Khanjani, S. Moharramipour, and M. P. Zalucki. 2010. Preimaginal development response to constant temperatures in Hypera postica (Coleoptera: Curculionidae): picking the best model. Environ. Entomol. 39: 177-189.

Zalom, F. G., and P. B. Goodell. 1983. Degree days: the calculation and use of heat units in pest management. University of California, Division of Agriculture and Natural Resources, Leaflet 21373.

Zamani, A. A., A. Talebi, Y. Fathipour, and V. Baniameri. 2007. Effect of temperature on life history of Aphidius colemani and Aphidius matricariae (Hymenoptera: Braconidae), two parasitoids of Aphis gossypii and Myzus persicae (Homoptera: Aphididae). Environ. Entomol. 36: 263-271.

Zamani, A., A. Talebi, Y. Fathipour, and V. Baniameri. 2006. Effect of temperature on biology and population growth parameters of Aphis gossypii Glover (Hom., Aphididae) on greenhouse cucumber. J. Appl. Entomol. 130: $453-460$. 